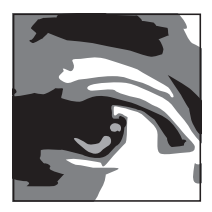

\title{
Addressing Maternal and Newborn Health: A Leadership Perspective
}

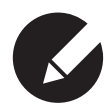

Leslie Mancuso, PhD, RN, FAAN, President and CEO, Jhpiego, Baltimore, MD, USA

Peter Johnson, PhD, CNM, Director of Global Learning and Nursing \& Midwifery, Jhpiego, Baltimore, MD, USA

Leah Hart, MSN, MPH, RN, Senior Program Officer, Jhpiego, Baltimore, MD, USA

Kate Austin, MA, Senior Communications Specialist, Jhpiego, Baltimore, MD, USA

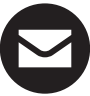

Correspondence may be directed to:

Leslie Mancuso

E-mail: Leslie.Mancuso@jhpiego.org

\begin{abstract}
Globally, each year 289,000 mothers die in childbirth and three million infants die in the first four weeks of life. The shortcomings in maternal and newborn health are particularly devastating in low-resource countries. This qualitative study describes the experience of an international nongovernmental organization, Jhpiego, which has been implementing public health programs to address maternal and newborn health outcomes for more than 40 years. Themes emerged from interviews with leaders of offices in a variety of countries with unique challenges related to health systems, human resources and infrastructure. Results emphasized the importance of partnerships with governments and international agencies for long-term program impact, as well as the recruitment of local talent for improving health systems to address problems that are best understood by the people who live and work in these countries. The discussion of program successes and challenges may inform best practices for promoting the health and wellness of women and families around the world.
\end{abstract}




\section{Introduction}

Maternal mortality has decreased by almost half over the past 20 years; yet 289,000 mothers still die each year during pregnancy and childbirth (Alkema et al. 2014). Most of these deaths occur in low-resources countries, and the disparities are vast: The lifetime risk of a woman living in sub-Saharan Africa dying as a result of pregnancy and childbirth is over 47 times greater than for a woman living in Canada (Alkema et al. 2014). In addition, 3 million newborns die annually within the first four weeks of life (Blencowe and Cousens 2013) and 2.6 million more are stillborn (McClure et al. 2015). Children who die in the first four weeks do so as the result of diseases and conditions that are often associated with quality of care around the time of childbirth and are readily preventable or treatable (Saleem et al. 2014). Globally, the number of newborn deaths declined from 4.7 million in 1990 to 2.8 million in 2013, but still account for $44 \%$ of under-five deaths (You et al. 2014). While progress has been made over the past two decades, the global health community has fallen short of 2015 Millennium Development Goal 4, reduce child mortality, and Goal 5, improve maternal health. The global development community now begins work to address 17 new Sustainable Development Goals and 169 targets to achieve by 2030 - including Goal 3.1, reduce the global maternal mortality ratio to less than 70 per 100,000 live births, and Goal 3.2 , end preventable deaths of newborns and children under five years of age - with all countries aiming to reduce neonatal mortality to at least as low as 12 per 1,000 live births and under-five mortality to at least as low as 25 per 1,000 live births (United Nations 2015). The achievement of these goals will enhance the potential that women and newborns avoid an increased risk of death or disability simply because of where they live.

Jhpiego, a global health non-profit affiliate of the Johns Hopkins University, has been working for over 40 years to end preventable deaths of women and their families. Jhpiego was founded in 1973 to introduce physicians, nurses and administrators from developing countries to reproductive health breakthroughs and strengthen their ability to introduce high-impact, evidence-based practices. Today, Jhpiego has field offices in 30 countries and has worked in more than 150 countries throughout Africa, Asia and Latin America and the Caribbean.

A technical leader in maternal and newborn health recognized worldwide, Jhpiego is currently leading the United States Agency for International Development's global flagship Maternal and Child Survival Program. Jhpiego has developed many widely used reproductive health policies, guidelines and resource packages that enable frontline health workers to take the timely and correct actions needed to save lives.

This study was conducted to identify best practices and challenges associated with the implementation of maternal and newborn health programs in the developing world, and specifically within Jhpiego. The study, based on interviews with a range of leaders responsible for managing Jhpiego's programs at national or country levels, describes effective practices as well as challenges in the implementation of national public health programs. The conclusions are pertinent to sustaining gains made in maternal and newborn health by governments and the global health community, as well as exploring the evidence-based approaches necessary to meet the challenge of the Sustainable Development Goals. The lessons learned from Jhpiego's organizational experience, conducted hand in hand with international and national partners, may be useful to those working to strengthen health systems in order to reach every woman, every newborn, everywhere, every time.

\section{Methods}

A research plan was submitted to the Johns Hopkins University Institutional Review Board with a human subject exempt determination. 
Leaders from a purposeful cross-section of Jhpiego offices were interviewed. There were two participants from Asia, three from East Africa, one from a Portuguese-speaking country in Africa and two from West Africa. Of the eight key informants, one was a senior member of the headquarters leadership team, six were directors of Jhpiego country offices and one was a national program manager (Table 1). All were asked to respond to a set of open-ended questions related to criteria for program effectiveness. Three interviews were conducted face to face and the remainder by telephone or computer voice over Internet protocol. All interviews were either audio recorded or captured via detailed notes taken by one member of the research team.

Individual interviews were transcribed when necessary and reviewed by all members of the research team using standard qualitative research methodologies. Coding was conducted manually with the data organized and sorted around thematic categories (Polit and Beck 2003). Dominant themes were extracted from transcripts and field notes using a constant comparative technique (Fram 2013). The research team discussed and reached consensus on emerging themes, categories and patterns.

The leaders interviewed for this study have worked for a wide variety of international nongovernmental organizations, donors, United Nations agencies and the World Health Organization. They have vast public health leadership experience (median 21.5, range 10-40 years) with a range of expertise important to Jhpiego's mission. These leaders collectively have experience in programming related to treatment of HIV, malaria and other infectious diseases that plague the developing world; maternal, newborn and child health; family planning and cervical cancer prevention. They also have a broad combination of health systems expertise related to health workforce development, stateand district-level capacity strengthening, competency-based education and training and quality improvement. All have significant experience in their Jhpiego leadership roles (median 5.5, range $3-23$ years).
Table 1. Key informant interviewees,
Jhpiego position and experience

\begin{tabular}{|l|l|l|l|}
\hline Name & Country & $\begin{array}{l}\text { Years } \\
\text { with } \\
\text { Jhpiego }\end{array}$ & $\begin{array}{l}\text { Years in } \\
\text { a Senior } \\
\text { Public } \\
\text { Health } \\
\text { Position }\end{array}$ \\
\hline $\begin{array}{l}\text { Headquarters } \\
\text { senior leadership }\end{array}$ & $\begin{array}{l}\text { Burkina } \\
\text { Faso/USA }\end{array}$ & 23 & 28 \\
\hline $\begin{array}{l}\text { Regional and } \\
\text { country director }\end{array}$ & Kenya & 8 & 14 \\
\hline Chief of party & Ethiopia & 3 & 26 \\
\hline Country director & Myanmar & 4 & 10 \\
\hline Country director & India & 6 & 40 \\
\hline Country director & Zambia & 5 & 25 \\
\hline Country director & Mozambique & 11 & 18 \\
\hline Country director & Ghana & 4 & 11 \\
\hline
\end{tabular}

\section{Results}

Results derived from the analysis of the responses of those interviewed were divided into two major themes related to good practices and challenges. Several equally compelling subthemes emerged in relationship to both good practices and challenges associated with sound implementation of public health programs in the developing world. All are essential to implementation of quality maternal health programs, and they contain processes that are valuable for addressing a full range of public health priorities in low-resource countries. The narrative that follows presents a synthesis of findings; exemplary quotations are provided that support our interpretation.

\section{Good Practices}

\section{Thinking Globally, Acting Locally}

A two-way flow of communication is essential in order to capture valuable lessons learned from those implementing programs. Global partnerships are important and result in maternal and newborn health consensus documents (standards and guidelines) that are valuable to partners implementing regionally, nationally and locally. Those partnering at the global level are encouraged to engage in a 
shared analysis of successes and failures in order to distill best practices and provide functional guidance to those pursuing results at the country, district, facility or community level. Global results require local adaptation.

Global work allows countries to not have to reinvent the wheel.

If things have gone through a global consensus-building process, then countries may be more ready and willing to adopt.

\section{Leading from Behind}

The importance of involving stakeholders, such as relevant country Ministries of Health and or Ministries of Education, professional associations, local community-level leaders, providers and consumers, and facilitating their role as leaders of the effort, was one of the strongest themes that emerged from the analysis. Technical advice and support from donors and implementing agencies were keys to successful start-up. However, understanding of local responsibility for leadership, at the outset of a program, is a key to longerterm ownership and sustainability.

The team [and stakeholders] believes that [our capacity-building approach] is working and they have bought in completely. This is how we save lives.

Additional effort to involve and gain support from the community, and those who are not initially enthusiastic about the proposed intervention, offers additional advantage to sustainability.

The system has to take it forward, no donor or partner from the outside can do it.

If you don't have the relationships and commitment, it doesn't matter what level of technical capacity you have. The technical improvements will only have a limited life.

\section{Partnerships and Transparency}

Consultation, coordination and inclusion are essential elements of successful partnership. International, regional and local partners should be selected early to enable participation in design, and should be chosen based on a thoughtful and critical analysis of their ability to make a unique contribution to program results. Relationships between organizations, while often established based on an analysis of ability to deliver measurable improvements in public health outcomes, are nurtured through mutual trust resulting from working together toward a common goal. There was strong consensus that involving Ministry counterparts as partners is crucial for success.

We are seen as a good partner because we are more open to share what we are doing and how we are doing.

Selecting partners who have a passion for achieving the results that are being targeted, have the opportunity to contribute, and have the capacity to make a unique contribution [is essential].

\section{A Systems-Based Approach to Implementation}

Donor-supported programs are often focused on a particular disease burden or perceived public health priority.

Implementers should consider their broader systems expertise in relationship to this goal and leverage this opportunity toward broader impact. For example, a limited scope of work aimed at reducing the impact of malaria on pregnancy can result in requests for a more comprehensive set of interventions aimed at maternal and newborn health. Likewise, trust established through visible results in maternal and newborn health may lead to requests to aim successful interventions at infectious diseases, reproductive health and the broader strengthening of health systems. Programs are advised to plan ahead for these opportunities and advocate for them throughout the 
span of a program. Respondents noted that there is often opportunity to use maternal and newborn health projects as a launching pad [for improving systems that support all service delivery].

\section{Designing for Sustainability}

Implementing partners have a responsibility to design for scalability from the outset and take actions to increase the likelihood that results can be achieved using resources likely to be available after program support is withdrawn. For this reason, successful maternal and newborn health programs focus on building local capacity of governments, professional associations, regulators and local nongovernmental organizations.

Think beyond the project.

A robust understanding of the community in need of support and its stakeholders is essential for sustainability. Mapping the opinions of stakeholders who are opposed to your ideas is as important as listening to those who are supportive. By placing "boots on the ground" at the community level, one can develop the trust and buy-in needed for real results. Fully engaging the community with humility and respecting the resourcefulness of those within it lead to true joint problemsolving for lasting results.

The system will have to carry it [gains] forward, and when the system takes over it may not be perfect, but we have to be prepared for it to be good enough.

\section{Advocating for Evidence-Based,} High-Impact Interventions

Implementers should build on the existing evidence base while testing innovations needed to generate new pathways for success. The infusion of a continuous quality improvement philosophy of practice was seen as the linkage between the introduction of changes to practice and their successful adoption at the facility level. For example, Jhpiego Uganda has worked across 27 facilities supporting quality improvement using an evidence-based, low-dose, high-frequency performance support approach (Bluestone et al. 2013) linked directly to Jhpiego's Standards-Based Management and Recognition (SBM-R ${ }^{\circledR}$ ) quality assurance methodology (Necochea et al. 2015). Remarkable changes were observed.

[The] changes observed were phenomenal. Facilities supported under this program were clean and well-organized by a staff of very motivated workers.

At the same time, there must be critical awareness of the context in which these changes are being introduced, as social, political, religious and regulatory factors each plays a role in the acceptability of the practice of any intervention at the national and community levels. The introduction of home-based distribution of misoprostol is an example of a highly evidenced-based intervention for prevention of postpartum hemorrhage (Smith et al. 2013). Sustainable introduction of this approach, and its acceptability at national and facility- and community-based levels, was possible in some countries only through efforts to fully analyze and adapt the introduction of this intervention in a manner that accommodated and acknowledged these cultural constraints.

\section{Data-Driven Programs}

Data can be used to ensure that high-impact interventions are provided on a consistent basis and that these interventions are resulting in measurable, quality outcomes. A results-based monitoring and evaluation plan with clear measures of success is of paramount importance before first steps are taken to implement any specific program. Data must be collected and analyzed on a regular, scheduled basis with sufficient input from a range of stakeholders who can help interpret the nuances of program data. 
Ideas, established at the beginning of the program, about what is likely to work may evolve over time with greater understanding of context.

When you plan, you have good ideas based on your experience but you need to be open to change.

Monitoring and evaluation increases the reputation of the institutions providing care and thereby increases access to care.

Highly successful programs reach beyond tracking inputs and aim toward robust measurement of outcomes or impact. For example, being able to measure a reduction in postpartum hemorrhage, or a midwife's ability to successfully manage a postpartum hemorrhage is far more powerful than simply counting the number of midwives who received training to perform that lifesaving skill. Careful and regular attention to monitoring of program outcomes can be highly motivating to staff.

\section{Championing Equity}

The impact of a maternal and newborn health program can be maximized by fully understanding the needs of populations and communities most vulnerable and underserved. A substantial number of leaders interviewed described the importance of promoting equity through their program portfolios.

Looking at the population that we are serving by education, gender, age and income [programs can aim] at those who need the care the most.

Tangible steps can be taken to facilitate equity. For example, one country is designing programs specifically aimed at empowering youth who live in urban slums, while another country is supporting the development of more "womanfriendly" midwifery education systems.

\section{Challenges}

Throughout the interviews, the key informants outlined specific challenges that presented barriers to the successful implementation of their work. Sub-themes identified are elaborated below. Exemplar statements are provided to demonstrate the complexity of the ways leaders have addressed these challenges.

Supporting High-Need, Low-Capacity Systems There are bottlenecks and challenges inherent in working in high-need, low-capacity systems, and implementers have to anticipate bottlenecks in the system. Implementers must put themselves in their counterparts' shoes and understand as much as possible how to overcome challenges without building long-term dependency. The most successful programs acknowledge limitations in countries or regions with weak infrastructure, scarce human resources or little political will. This may require more intense support to local stakeholders including assigning program-employed staff within stakeholders' offices or placing greater reliance on higher-level short-term technical assistance from international experts.

If the government had the capacity, they wouldn't be asking for help.

\section{Achieving Impact within Complex Health Systems}

Global health implementing partners have always struggled to document impact when supporting complex systems. For example, the inability to document impact as a result of improvements to a national midwifery education system may lead to frustration by donors, implementers and stakeholders within the system. Some interviewed described their use of an evidence-based conceptual model that connects inputs to education of nursing, midwifery or other students in the health professions to outcomes upon graduation and later to community and health systems impact (Johnson et al. 2013). 
Maintaining Focus

It is easy for an implementer to lose focus and spread efforts too thinly. One leader interviewed described two efforts to mitigate the impact of malaria on pregnancy occurring in the same country at two points in time. The second effort, which used a precalculated amount of resources aimed at two districts, was far more powerful than a previous effort with fewer resources targeted at national-level goals. One must fully understand and act upon the complete set of needs underlying a problem. These may include human resources, logistics and commodities. Implementers can't just parachute in and make an impact in a developing country.

Remaining Humble - Balancing Technical Quality with Efforts to Communicate Success Organizations must balance their efforts between promoting their good work and actually building capacity to achieve results over time. A certain amount of humility is essential. Remember to lead from behind, and applaud the work of your local counterparts and partners. Have effective monitoring and evaluation rubrics established and focus on presenting unbiased analysis of program results.

\section{Managing Expectations}

Expectations must be actively managed from the beginning of a program. Implementers must strive for front-end consensus regarding intended program results and the indicators used to measure them. If donor representatives lack technical experience, they need to be supported and appropriately advised. Communication pathways need to be clear and actively traversed.

Everything can collapse in a moment based on misinformation.

\section{Discussion}

This study was conducted to identify best practices and challenges associated with the implementation of maternal and newborn programs in the developing world. While the results are limited to the perspective of a single international nongovernmental organization, Jhpiego, the data collected suggest that good public health practices translate to good maternal and newborn health practices and vice versa. These practices, when implemented within strong partnerships and using global guidelines, can create the change necessary for health systems to provide highquality health services to vulnerable women and newborns.

The findings highlighted that change in practice should begin with a data-driven approach, including the development of a monitoring and evaluation plan, ideally at the start of a program. Comprehensive monitoring and evaluation allow local stakeholders to collaborate together to identify the results they expect, which should emphasize impact and not input, and provide the specific details on how to measure and evaluate progress and results. Celebrate with local counterparts any necessary mid-course corrections that were identified based on these monitoring and evaluation data, as no one can expect to get a new approach perfect in the beginning. This process is also beneficial in initiating change within the country.

The results of the study also emphasized the important role of an implementing partner, which can facilitate access to global evidence, standards, policies and procedures, for country decision-makers to use for their national programs. Access to this type of information provides the foundation for developing country- and community-specific approaches to improving maternal and newborn health outcomes. At the same time, best practices created at the country level and based on program experience can and should improve policy and planning within the global community as well.

Implementing maternal and newborn health programs using a health systems approach in which lessons learned from other parts of the system are easily applied or 
utilized in maternal and newborn health can be beneficial. Also, despite the fact that most programs are focused on a specified scope of work, implementers that utilize all opportunities to coordinate with other government and authorized stakeholder activities promote a broader and more lasting impact. A robust systems approach to changing healthcare practices should include integration and a focus on equity.

The study reinforced the understanding that change is not brought about by one person, government or agency, but by collective, collaborative effort. Partnerships that are built on clear goals, trust and shared commitment facilitate information-sharing, creative problem-solving and use of best practices and lessons learned (Agarwal et al. 2015).

The research highlighted the need for program implementers to be cognizant of their role in maternal and newborn health partnerships and assist local country partners to be the face and champions of change. Implementers should provide support from behind to catalyze sustainable change.

The data suggested that evidenced-based change can be threatened by limited human workforce capacity within the existing health system. Managing expectations, acknowledging limitations and maintaining communication with local stakeholders are essential.

It is possible to transfer lessons learned from low-resource countries to developed countries where there are geographic areas that have limited access to maternal and newborn healthcare services. For example, those working on solutions to the public health problems plaguing low-income or rural populations suffering from health disparities could consider applying or adapting lessons learned to their context. Partnerships, evidenced-based systemic approaches and data-driven initiatives should be considered as key elements in these activities.

\section{Conclusion}

The paper describes good practices for global maternal and child health programs from the grounded perspective of Jhpiego field leaders who are experienced public health practitioners and whose country teams are responsible for implementation of large-scale programs. The successful approaches defined by Jhpiego leaders are a mix of innovative and evidence-based practices that can lead to meaningful and lasting improvements in healthcare systems that serve women and children in resource-challenged settings. There is also an acute awareness of challenges and suggestions for negotiating bottlenecks. Together, the successes and challenges discussed provide a valuable roadmap to promoting the health and wellness of women and families around the world.

\section{References}

Agarwal, K., N. Caiola and A. Gibson. 2015. "Best Practices for a Successful MNCH Partnership That an External Evaluation Could Never Find; Experiences from the Maternal and Child Health Integrated Program." International Journal of Gynecology \& Obstetrics 130(Suppl 2): S11-S16.

Alkema, L., D. Chou, A. Gemmill, D. Hogan, C. Mathers, S. Mills, A.B. Moller, L. Say and E. Suzuki. 2014. Trends in Maternal Mortality: 1990 to 2013. Estimates by WHO, UNICEF, UNFPA, The World Bank and the United Nations Population Division. Geneva: World Health Organization. Retrieved August 31, 2015. <http://apps.who.int/iris/bitst ream/10665/112682/2/9789241507226_eng.pdfs.

Blencowe, H. and S. Cousens. 2013. "Addressing the Challenge of Neonatal Mortality." Tropical Medicine and International Health 18(3): 303-12.

Bluestone J., P. Johnson, J. Fullerton, C. Carr, J. Alderman and J. BonTempo. 2013. "Effective In-Service Training Design and Delivery: Evidence from an Integrative Literature Review." Human Resources for Health 11: 51. Retrieved August 31, 2015. <http:/www.human-resources-health.com/ content/pdf/1478-4491-11-51.pdf>.

Fram, S.M. 2013. "The Constant Comparative Analysis Method Outside of Grounded Theory." The Qualitative Report 18(1): 1-25. Retrieved August 31, 2015. <http://nsuworks.nova.edu/tqr/ vol18/iss $1 / 1 />$. 
Johnson P., L. Fogarty, J. Fullerton, J. Bluestone and M. Drake. 2013. "An Integrative Review and Evidence-Based Conceptual Model of the Essential Components of Pre-Service Education." Human Resources for Health 11: 42. Retrieved August 31, 2015. <http://www.human-resources-health.com/ content/11/1/42>.

McClure, E.M., S. Saleem, S.S. Goudar, J.L. Moore, A. Garces, F. Esamai et al. 2015. "Stillbirth Rates in Low-Middle Income Countries 2010-2013: A Population-Based, Multi-Country Study from the Global Network." Reproductive Health 12(Suppl 2): S7. doi:10.1186/1742-475512-S2-S7.

Necochea, E., V. Tripathi, Y.M. Kim, N. Akram, Y. Hyjazi, M. da Luz Vaz et al. 2015 "Implementation of the Standards-Based Management and Recognition Approach to Quality Improvement in Maternal, Newborn, and Child Health Programs in Low-Resource Countries." International Journal of Gynecology \& Obstetrics 130(Suppl 2): S17-S24. Retrieved August 31, 2015. <http://www.sciencedirect.com/ science/article/pii/S0020729215001988>.

Polit, D.F. and C.T. Beck. 2003. "Key Concepts and Terms in Qualitative and Quantitative Research." In Nursing Research: Principles and Methods, Seventh Edition. Philadelphia, PA: Lippincott Williams \& Wilkins. Retrieved August 31, 2015. <http://www.scribd.com/ doc/10264232/Research\#scribd>.
Saleem, S., E.M. McClure, S.S. Goudar, A. Patel, F. Esamai, A. Garcesk et al. 2014. "A Prospective Study of Maternal, Fetal, and Neonatal Deaths in Low- and Middle-Income Countries." Bulletin of the World Health Organization 92: 605-12. Retrieved September 14, 2015. <http://www.who. int/bulletin/volumes/92/8/13-127464.pdf>.

Smith, J.J., R. Gubin, M.M. Hoston, J. Fullerton and N. Prata. 2013. "Misoprostol for Postpartum Hemorrhage Prevention at Home Birth: An Integrative Review of Global Implementation Experience to Date." BMC Pregnancy and Childbirth 13: 44. <http://www.biomedcentral. com/1471-2393/13/44>.

United Nations. 2015. Transforming Our World. The 2030 Agenda for Sustainable Development. Retrieved September 14, 2015. <https:// sustainabledevelopment.un.org/content/ documents/7891Transforming\%200ur\%20 World.pdf>.

You, D., L. Hug, Y. Chen, H. Newby and the United Nations Inter-Agency Group for Child Mortality Estimation. 2014. Levels and Trends in Child Mortality. Report 2014. New York: United Nations Children's Fund. Retrieved August 31, 2015. <http://www.unicef.org/media/files/Levels_ and_Trends_in_Child_Mortality_2014.pdf>.

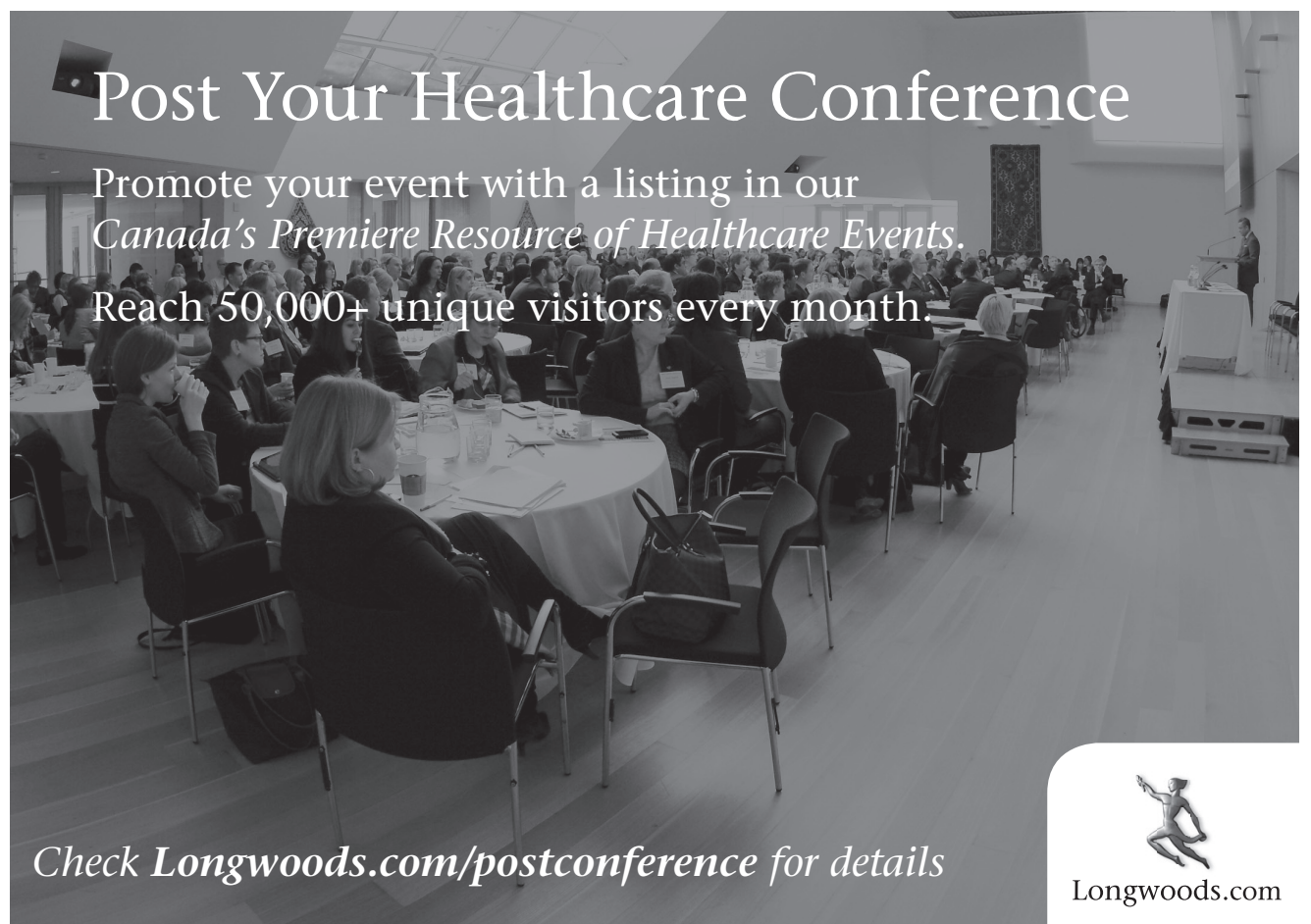

